\title{
Management of hemolytic-uremic syndrome in children
}

This article was published in the following Dove Press journal: International Journal of Nephrology and Renovascular Disease 12 June 2014

Number of times this article has been viewed

\section{Silviu Grisaru \\ University of Calgary, Alberta Children's Hospital, Calgary, Alberta, Canada}

\begin{abstract}
Acute renal failure associated with a fulminant, life-threatening systemic disease is rare in previously healthy young children; however, when it occurs, the most common cause is hemolytic-uremic syndrome (HUS). In most cases (90\%), this abrupt and devastating illness is a result of ingestion of food or drink contaminated with pathogens that produce very potent toxins. Currently, there are no proven treatment options that can directly inactivate the toxin or effectively interfere with the cascade of destructive events triggered by the toxin once it gains access to the bloodstream and binds its receptor. However, HUS is self-limited, and effective supportive management during the acute phase is proven to be a life saver for children affected by HUS. A minority of childhood HUS cases, approximately $5 \%$, are caused by various genetic mutations causing uncontrolled activation of the complement system. These children, who used to have a poor prognosis leading to end-stage renal disease, now have access to exciting new treatment options that can preserve kidney function and avoid disease recurrences. This review provides a summary of the current knowledge on the epidemiology, pathophysiology, and clinical presentation of childhood HUS, focusing on a practical approach to best management measures.
\end{abstract}

Keywords: hemolytic, uremic, E.coli O157:H7, thrombotic, microangiopathy, complement system

\section{Introduction}

Hemolytic-uremic syndrome (HUS) is one of the most common etiologies for acute kidney injury and an important cause of acquired chronic kidney disease in children. ${ }^{1}$ HUS is generally classified into two main types: typical or diarrhea-associated (D+HUS) and atypical (aHUS) or diarrhea-negative HUS. In children, 90\% of HUS cases are associated with a prodrome of diarrhea caused by infections with Shiga toxin-producing Escherichia coli that are able to attach to the intestinal wall; these are known as enterohemorrhagic E. coli (EHEC). ${ }^{1}$ A rare form of HUS caused by streptococcus pneumoniae, usually following invasive pulmonary infection, is occasionally classified with D+HUS in the group of infectious HUS, or is included in the aHUS group as it is not preceded by diarrhea. ${ }^{2}$ The majority of the remaining cases are affected by aHUS, which can be sporadic or familial. Most cases of aHUS are caused by genetic or acquired dysregulations of the complement system. ${ }^{3}$ Thrombotic microangiopathy (TMA) is the common pathogenetic pathway leading to all forms of HUS as well as thrombotic thrombocytopenic purpura (TTP). ${ }^{4}$ However, TTP is rare in children and is usually caused by congenital mutation in the ADMTS13 gene, whereas in adults it occurs more frequently due to abnormal autoantibodies against the ADMTS13 enzyme. ${ }^{4}$ This paper will review the clinical presentation, epidemiology,
Correspondence: Silviu Grisaru University of Calgary, Alberta Children's Hospital, 2888 Shaganappi Trail NW, Calgary, Alberta, Canada T3B 6A8 Email sgrisaru@ucalgary.ca (c) (i) (2) 2014 Grisaru. This work is published by Dove Medical Press Limited, and licensed under Creative Commons Attribution - Non Commercial (unported, v3.0) License. The full terms of the License are available at http://creativecommons.org/licenses/by-nc/3.0/. Non-commercial uses of the work are permitted without any further permission from Dove Medical Press Limited, provided the work is properly attributed. Permissions beyond the scope of the License are administered by Dove Medical Press Limited. Information on how to request permission may be found at: http://www.dovepress.com/permissions.php 
and pathogenesis of HUS in children, focusing on current management options.

\section{Clinical presentation D+HUS}

D+HUS is usually preceded by a severe form of infectious gastroenteritis that typically begins 3 days after exposure to food or water contaminated with EHEC. However, following ingestion of EHEC, incubation periods ranging from 1-12 days have been reported. ${ }^{5,6}$ Symptoms are nonspecific, including nausea, cramping, abdominal pain, and diarrhea that is initially watery but becomes bloody in more than $70 \%$ of cases within 2-3 days from beginning of symptoms. ${ }^{7-9}$ Infections with Shiga toxin-producing E. coli belonging to the EHEC family can cause extensive colonic injury with excruciating cramping pain and a severe hemorrhagic colitis; however, milder forms with minimal symptoms and non-bloody diarrhea have been described. ${ }^{7,10,11}$ In $85 \%-90 \%$ of cases, the gastroenteritis is self-limited and the symptoms subside or disappear 5-8 days from start of symptoms, leading to full recovery.,11-14 Complications of the infectious colitis itself, including bowel perforation or massive hemorrhage, can be fatal; however, the most common and serious complication of EHEC infections is HUS, which develops in $10 \%-15 \%$ of affected patients $7-10$ days after beginning of symptoms. ${ }^{15}$

Patients that go on to develop HUS continue to be very sick; many are lethargic or irritable. Lab work is characterized by thrombocytopenia with platelet counts less than $150 \times 10^{9} / \mathrm{L}$, hemolytic anemia with schistocytes on blood smear, and progressing azotemia. In mild cases of D+HUS in previously healthy children, the azotemia may be missed or difficult to document as serum creatinine levels can be within normal range despite a more than 50\% increase from baseline. ${ }^{16} \mathrm{D}+\mathrm{HUS}$ is a systemic disease that can affect many organs; however, some of the most serious complications relate to involvement of the central nervous system. Lethargy, which is observed in many patients on presentation, can progress to development of stupor and coma as well as seizures and strokes. ${ }^{17}$ Acute kidney injury is characterized by progression to oligoanuria and severe electrolyte imbalances that require establishment of acute renal replacement therapy in $50 \%-70 \%$ of patients. ${ }^{18}$ Despite the fulminant disease course and multi-organ involvement, D+HUS is self-limited in most cases, with eventual gradual improvement and full recovery. ${ }^{18}$ Nevertheless, up to $25 \%$ of patients are left with ongoing sequelae such as chronic renal failure, hypertension, and, rarely, chronic pancreatitis and diabetes. ${ }^{18}$
Central nervous system complications resolve in most cases; however, these are responsible for the majority of D+HUSrelated fatalities, and permanent neurological sequelae have been reported in more than $20 \%$ of cases. ${ }^{17}$

\section{aHUS}

aHUS, by definition, is not preceded by the characteristic bloody diarrhea of EHEC infection; however, since in the majority of cases it involves dysregulation of the complement system, it is frequently triggered by an infectious event including gastroenteritis with diarrhea. ${ }^{19}$ Therefore, initially it may be difficult to differentiate from D+HUS. More than $60 \%$ of patients with aHUS present in childhood - the majority at less than 2 years of age, which is also common for D+HUS. ${ }^{19,20}$ Nevertheless, unlike aHUS, D+HUS rarely affects children younger than 1 year of age and almost never presents before 6 months of age. ${ }^{21}$ The presenting symptoms are nonspecific, related to the triggering infectious event or the developing systemic TMA, resembling D+HUS symptoms.

\section{Epidemiology}

HUS is a rare disease with an incidence ranging from $0.7-8$ cases/100,000 population per year with significant geographical and seasonal variability. The highest incidence of D+HUS is reported among children younger than 6 years who typically present in the late summer and autumn months. ${ }^{8,14,16,22-25}$ Prevalence of D+HUS is closely related to the incidence of EHEC infections and the main reservoir for EHEC pathogens is the gastrointestinal tract of healthy cattle. ${ }^{26}$ Higher incidence of D+HUS in rural areas with a developed cattle industry has been reported. ${ }^{8,23}$ The highest incidence of D+HUS in the world was reported in Argentina, while, in Canada, it has been observed in the province of Alberta; both geographic regions have developed beef production industries. ${ }^{16,27}$ Large outbreaks originating in contaminated food have been extensively publicized; one of the most well-known outbreaks in the US was caused by contaminated ground beef hamburgers served in a restaurant chain, hence the popular name for D+HUS: "hamburger disease". 5 However, contrary to popular belief, most cases of D+HUS are sporadic or occur in small clusters and are not related to poorly cooked contaminated ground beef. $8,14,15,22,24,28,29$ The majority of sporadic cases, as well as small and large outbreaks, are caused by other contaminated foods and beverages, such as vegetables, cider, or milk, ${ }^{30}$ and transmission from person to person has also been reported..$^{5,12,31}$ Moreover, not all outbreaks of D+HUS are associated with EHEC infections; other 
pathogens may be responsible, the most common of which is Shigella dysenteriae type 1 (SD1). ${ }^{32}$

aHUS is responsible for $10 \%$ of the total number of HUS cases, with an annual incidence that is roughly one-tenth of the incidence of D+HUS. ${ }^{33} \mathrm{Up}$ to $40 \%$ of these cases ( $5 \%$ of the total HUS incidence) are caused by invasive pneumococcal infections, and the rest are generally caused by complement dysregulations presenting sporadically or inherited in familial clusters. ${ }^{33}$ In North America and Europe, the incidence of noninfectious aHUS has been estimated to be two per million population per year. ${ }^{33,34}$ Patients can present at all ages; however, the majority of new cases present in childhood, with an estimated incidence of seven per million children per year in the European Community. ${ }^{34}$

\section{Physiopathology D+HUS}

Gasser et al were the first to describe the triad of symptoms and coin the term "hemolytic-uremic syndrome" in 1955; 35 however, only in 1983 were Karmali et al able to identify the toxin produced by EHEC as a causative factor. ${ }^{36,37}$ Notwithstanding Karmali et al's important discovery, D+HUS was reported to be associated with SD1 infectious diarrhea as early as $1975 .{ }^{32,38}$ The toxin isolated from stools of patients with EHEC infections and D+HUS was first named "verotoxin" due to its extremely toxic effect on Vero cells - an epithelial cell line isolated from the kidneys of an African green monkey. ${ }^{37}$ Subsequently, two toxins were identified and reclassified as "Shiga-like toxins" (STX1 and STX2) due to their close similarity to the Shiga toxin produced by SD1. ${ }^{39}$ The Shiga toxins are produced by pathogens in the gut and are absorbed into the blood circulation, which delivers them to various organs, including the kidneys.

The Shiga toxins are composed of $5 \beta$-subunits that bind with high affinity to the globotriaosylceramide receptor (Gb3) and an $\alpha$-subunit, which, after being internalized by cells, interferes with the ribosomal apparatus, effectively blocking protein synthesis leading to cell death. ${ }^{39}$ The currently accepted mechanism leading to HUS is a TMA triggered by endothelial cell death, exposure of the sub-endothelial space, and activation of the thrombotic cascade. ${ }^{40}$ Extensive microangiopathic intravascular thrombosis is responsible for the hemolysis of red cells by fragmentation, platelet consumption, and decreased glomerular perfusion leading to kidney injury. ${ }^{40}$ However, in addition to a prothrombotic effect, the presence of STX in microvasculature has been shown to be vasoconstrictive, proadhesive, and proinflammatory. Recent scientific evidence suggests that the extent of endothelial cell injury observed in STX-related HUS exceeds expectations from interference with protein synthesis alone. ${ }^{40}$ In vitro experiments demonstrated that bacterial lipopolysaccharide (endotoxin) acts synergistically with SD1 and EHEC toxins to enhance endothelial damage and the coagulative microangiopathy. ${ }^{41}$ One of the additional emerging mechanisms for cell injury in STX-related HUS involves activation of the complement system. ${ }^{40,42}$ In fact, evidence involving activation of the complement system in D+HUS forms the basis for a common pathogenetic mechanism that unifies all forms of TMA, including aHUS and TTP. ${ }^{42}$

Pathogens producing the STX2 toxin have been associated with more severe cases of D+HUS. E. coli O157:H7 is a pathogen that produces both forms of STX and is the most common serotype isolated from stools of D+HUS patients; however, many other serotypes have been reported to trigger D+HUS: O11:H8, O103-H2, O123, O26, and more. ${ }^{23}$ In the most recent mega-outbreak from Germany that occurred in 2011, the responsible pathogen was E. coli 0104:H4, which previously was not known to cause large outbreaks. ${ }^{40}$

\section{aHUS}

The pathogenesis of aHUS associated with invasive Streptococcus pneumoniae infections is related to the effect of the pneumococcal enzyme neuraminidase. It is postulated that by exposing the T-antigen on the surface of endothelial cells, this enzyme renders the endothelial cells vulnerable to injury by an immune response, which triggers the cascade of events leading to TMA and HUS. ${ }^{2}$

Approximately $50 \%$ of the rest of aHUS cases are caused by genetic variations of genes encoding proteins that participate in the tight control of the complement system. ${ }^{21}$ As shown in Figure 1, mutations in genes encoding complement factors $\mathrm{H}, \mathrm{I}$, and B, thrombomodulin, C3, and membrane cofactor protein have been reported to cause abnormal activation of the complement system. ${ }^{3}$ Autoantibodies against factor $\mathrm{H}$ with or without associated mutations in complement factor H-related proteins have also been described. ${ }^{3}$ Recently, a mutation in the gene encoding the enzyme diacylglycerol kinase $\varepsilon$ has been shown to be responsible for aHUS in a small number of familial cases by a complement unrelated mechanism. ${ }^{43}$

\section{Management and prognosis Management of EHEC infections and prevention of HUS}

Gastrointestinal infection with EHEC causes one the most severe forms of gastroenteritis, associated with excruciating 


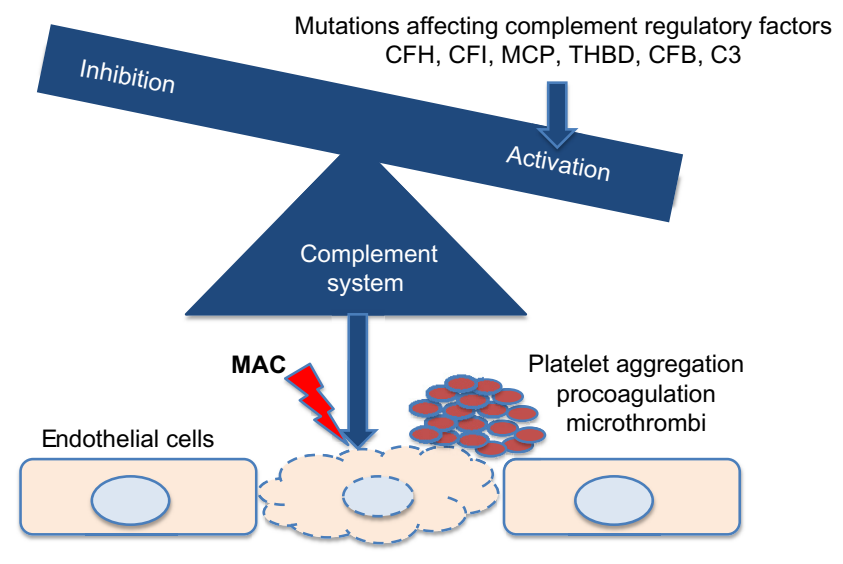

Figure I Genetic variations affecting complement factors or complement regulatory proteins cause complement activation, leading to thrombotic microangiopathy and hemolytic-uremic syndrome.

Abbreviations: $\mathrm{C} 3$, complement component 3; CFB, complement factor $\mathrm{B}$; $\mathrm{CFH}$, complement factor $\mathrm{H}$; $\mathrm{CFI}$, complement factor I; MAC, complement membrane attack complex; MCP, membrane cofactor protein; THBD, thrombomodulin.

abdominal pain and patient discomfort; yet, in most cases, it is self-limited, resolving without specific intervention. This fact must be taken into consideration in management, and intervention that may eventually aggravate or complicate outcomes must be avoided. For example, antiperistaltic agents have been shown to increase risks for systemic complication associated with EHEC infections and should therefore be avoided. ${ }^{44}$ Antibiotic treatment of EHEC infections that should also be avoided is discussed in detail in the antibiotic treatment section. Best management of patients with EHEC infections includes close monitoring for development of complications such as HUS coupled with supportive therapy. Fluid management is one of the most important components of supportive management in EHEC infections in the days before development of D+HUS. This period is characterized by diarrhea associated with nausea, vomiting, and extreme abdominal cramping pain, which are likely to lead to dehydration, intravascular volume depletion, and reduced renal perfusion. This situation can further intensify the prothrombotic environment created by STX-associated endothelial injury. ${ }^{45,46}$ Early volume expansion in patients affected by EHEC, implemented within the first 4 days from the onset of diarrhea, can improve renal and general outcomes of D+HUS. ${ }^{45,46}$ Type of fluids and way of administration should follow the general guidelines for hydration and rehydration in children with acute gastroenteritis..$^{47,48}$

\section{Antibiotic treatment}

Antibiotic treatment of EHEC infections before and after development of D+HUS has been a subject of great interest for researchers. However, most available data were obtained from retrospective and some prospective cohort studies dem-

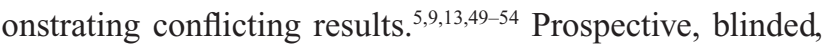
and randomized studies have not been conducted, and observational studies have been affected by bias toward use of antibiotics in initially "sicker" patients. A number of metaanalyses and systematic reviews have attempted to summarize the results of available studies, reaching inconclusive results and stating that more prospective, appropriately powered studies are needed. ${ }^{55-57}$ Most studies found no difference or favored a negative impact of antibiotics on risk for D+HUS and outcome. ${ }^{55,56}$ Only one retrospective cohort analysis of a large outbreak that occurred in Japan, demonstrated benefit for using the antibiotic fosfomycin within the first 2-3 days from beginning of EHEC infection symptoms. ${ }^{50,58}$ The negative impact of antibiotic use on risk and outcomes of HUS is not well understood. In vitro exposure of bacteria to antibiotics induces lysis with release of toxin, which, in the gut, could potentially be more likely to be absorbed. ${ }^{54}$ However, a toxin binder designed to diminish toxin absorption was not proven effective in a prospective randomized controlled trial. ${ }^{59}$ Antibiotics have not been shown to directly influence interaction between toxins and their $\mathrm{Gb} 3$ receptor, suggesting that the antibiotic influence on risk and outcome of HUS is mediated by modulation of toxin bioavailability. ${ }^{60-62}$ Recently, further evidence for a possibly beneficial role of early use of antibiotics in patients with D+HUS was provided by the retrospective analysis of antibiotic use during the 2011 German mega-outbreak. ${ }^{63}$ Nevertheless, based on best available evidence, the current recommendations are to avoid use of antibiotics in treatment of EHEC infections.

\section{Shiga toxin binding and blocking agents}

STX1 and STX2 are highly potent toxins in very small concentrations. Blocking STX access into the bloodstream or inactivation of blood-borne STX are major areas of interest in the search for D+HUS treatment options. SYNSORB Pk (Synsorb Biotech Inc., Calgary, AB, Canada) was a synthetic potent STX binder that was designed to bind STX in the gut, thus blocking absorption of STX; unfortunately, a large Phase III trial with this agent failed to demonstrate any benefit. ${ }^{59}$

Blocking the effect of blood-borne STX with inactivating antibodies has also been attempted, and, currently, a trial with monoclonal anti-STX1 and anti-STX2 antibodies is taking place in South America ${ }^{64,65}$ Nevertheless, the main challenge with STX binding and blocking agents has been timing of administration, which needs to occur before the STX effect is further amplified by a cascade of events involving the thrombotic, inflammatory, and complement systems..$^{59,66}$ 


\section{Management of D+HUS}

Mortality associated with the acute phase of D+HUS has decreased over the years since first description of this syndrome, from up to $30 \%$ to less than $1 \%$ in some series. ${ }^{18}$ Early recognition of symptoms followed by prompt and diligent supportive therapy is most likely responsible for this achievement. Specific supportive therapy strategies in children with D+HUS such as fluid management, renal replacement therapy and blood products transfusions, are detailed in their respective sections later in this review. A practical flowchart approach to the child at risk or presenting with HUS is shown in Figure 2.

Early, effective supportive intervention depends on a high level of suspicion of D+HUS followed by diligent close monitoring for emerging HUS signs, combined with prompt and accurate diagnosis. ${ }^{30,46,66}$ Isolation of EHEC from stool

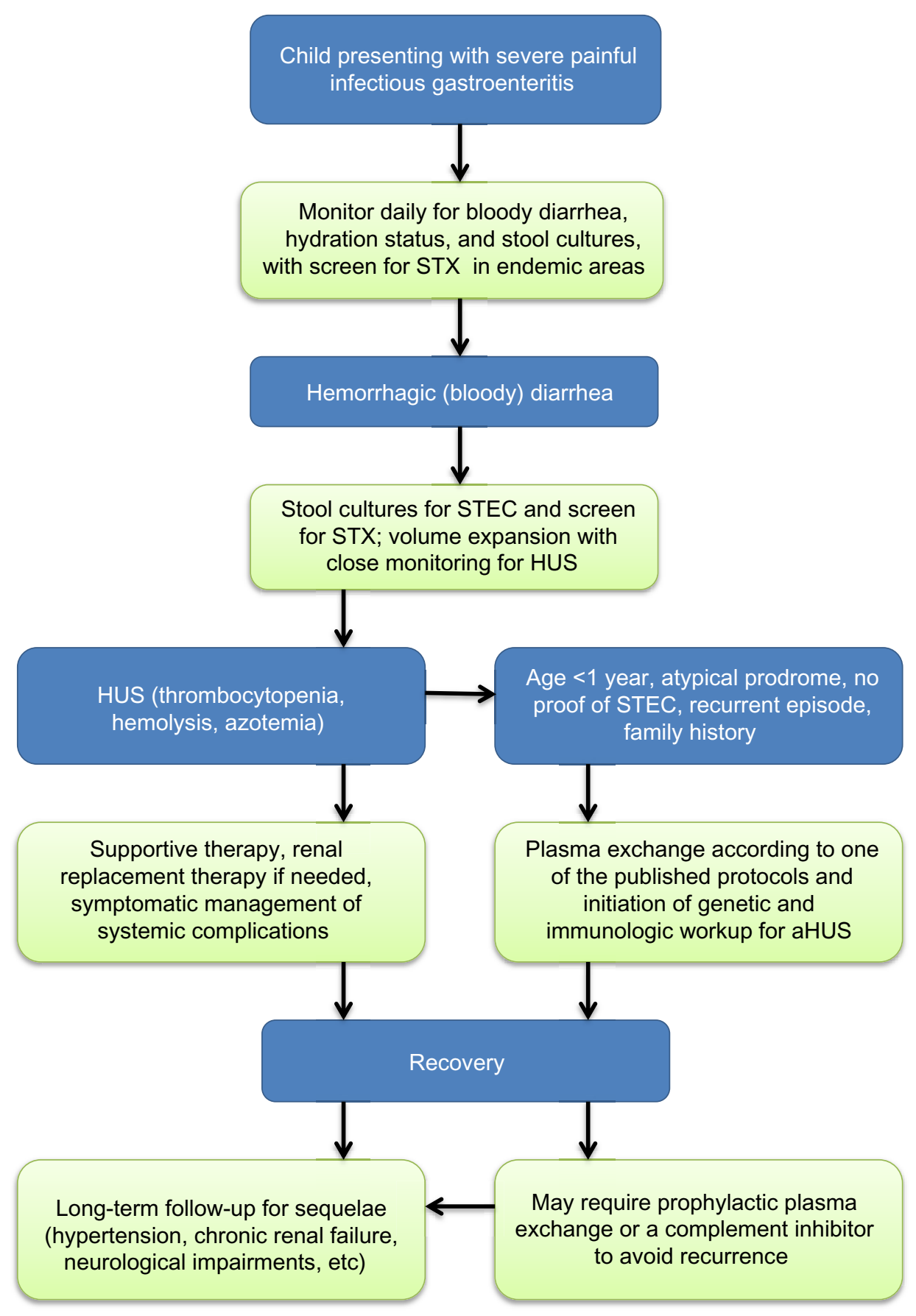

Figure 2 Practical approach to the child at risk for or presenting with HUS.

Abbreviations: aHUS, atypical HUS; HUS, hemolytic-uremic syndrome; STEC, Shiga toxin-producing Escherichia coli; STX, Shiga-like toxins. 
samples requires time and special culture conditions and has limited rates of success; however, new methods of screening stool samples for STX by enzyme-linked immunosorbent assay and polymerase chain reaction have greatly improved the likelihood and speed of detection. ${ }^{67}$

\section{Fluid management in D+HUS}

Fluid expansion can be very beneficial and is indicated as supportive therapy for EHEC infection with gastroenteritis; however, once D+HUS develops and oligoanuria is identified, careful fluid management, including restriction, should be considered to avoid fluid overload. Fluid overload that is present at the time of initiation of urgent renal replacement therapy in critically ill children with multisystem involvement has been shown to be a bad prognostic factor. ${ }^{68,69}$ Among other benefits, close monitoring during the EHEC infection is important to facilitate early detection of evolving HUS and allow timely necessary adjustments to fluid management. As HUS and acute kidney injury evolve, hypertension frequently develops along with fluid and salt retention. In this situation, the general approach to management of acute kidney injury in children should be applied..$^{70-72}$ Careful attention should be given to the type of fluids administered, aiming to minimize salt load, while total administered volume should not exceed the total of all losses such as urine output, insensible losses, ongoing diarrhea, etc. Volume required for adequate nutrition should be given priority and be included in the total fluid balance. Judicious use of loop diuretics can help manage hypertension as well as maintain adequate urine output, which can facilitate fluid management and nutrition and improve outcomes. ${ }^{73}$ Additional use of antihypertensive agents may be needed to control hypertension.

\section{Renal replacement therapy}

Renal replacement therapy is required in $50 \%-70 \%$ of cases in the acute phase of HUS. ${ }^{18}$ There are no specific indications or benefit for early initiation of acute dialysis in D+HUS. ${ }^{66}$ General indications for acute renal replacement therapy in the management of acute kidney injury should be applied. Oligoanuria, severe azotemia, electrolyte abnormalities, acidosis, and need for nutritional support are among the common indications for acute dialysis. ${ }^{30}$ There is no clear benefit for a specific type of renal replacement therapy; however, peritoneal dialysis has been extensively and successfully used in children with D+HUS. ${ }^{59}$ Insertion of a peritoneal dialysis catheter can usually be safely performed in thrombocytopenic patients without the need for platelet transfusion, and trained staff can safely perform peritoneal dialysis on general pediatric wards. ${ }^{74}$ Complications and technical failure are rare despite the severe intestinal injury caused by the EHEC infection, which is not a contraindication for peritoneal dialysis and does not interfere with the effectiveness of this modality. ${ }^{75}$ Hemodialysis or continuous veno-venous hemodiafiltration are also very efficient, but require appropriate venous access and admission to an intensive care unit. Nevertheless, in patients with aHUS or in whom aHUS is suspected, hemodialysis or veno-venous hemodiafiltration may be preferred modalities since the venous access can also be used for administration of plasma exchange, which is generally indicated in these patients. Finally, despite the fact that there is no proven benefit for early renal replacement therapy, efforts should be made to start dialysis before development of fluid overload, which may be associated with a worse prognosis in a critically ill child. ${ }^{68,69}$

\section{Transfusions}

Platelet consumption and hemolysis are integral consequences of the TMA in HUS. The thrombocytopenia in these cases can be extreme, yet platelet transfusions are not indicated unless there is evidence of active bleeding. Transfused platelets can enhance the thrombotic events occurring in various microvasculature beds of affected patients. ${ }^{30}$ Severe anemia secondary to hemolysis, on the other hand, can further destabilize patients by negative effects on the cardiovascular and respiratory systems. Erythrocyte transfusions are considered an important component of the supportive therapy in HUS, and have been reported to be required in $80 \%$ of patients. ${ }^{7,75}$ Use of erythropoietin early in the course of HUS has been proposed as a possible measure toward reducing the need for erythrocyte transfusions. ${ }^{76}$

\section{Treatment of aHUS - plasma exchange (PE)}

Current evidence does not support use of fresh frozen plasma infusions or PE in patients with D+HUS. In contrast, PE should be instituted without delay in patients with non-pneumococcal aHUS. ${ }^{21}$ Initial management of aHUS is frequently similar to D+HUS due to the infectious prodrome that typically triggers the first episode; however, once aHUS is suspected, PE treatment should be offered, given its proven efficacy in aHUS. ${ }^{21}$

In a majority of non-pneumococcal aHUS cases, abnormal complement activation is responsible for the TMA, which can be efficiently controlled with daily or even twice-daily PE. ${ }^{21,77}$ Therefore, when aHUS is suspected, PE should be 
instituted immediately, as the diagnostic workup may be quite lengthy. ${ }^{21}$

\section{Complement inhibitors}

Currently, the single commercially available complement inhibitor is eculizumab, a recombinant, humanized monoclonal antibody against complement component C5. This antibody effectively blocks cleavage of complement factor C5 and the formation of the complement membrane attack complex C5b-9. ${ }^{78}$ Clinical trials have shown eculizumab to be more efficient than plasma therapy in prevention and treatment of aHUS episodes caused by dysregulations of the complement system. ${ }^{78} \mathrm{~A}$ favorable outcome after use of eculizumab in three patients with severe D+HUS and central nervous system involvement was described in a case report. ${ }^{79}$ However, a retrospective review of the extensive uncontrolled use of eculizumab, during the last large outbreak of D+HUS in Germany, did not demonstrate a benefit for patients who were treated with this agent, compared to matched patients who did not receive eculizumab. ${ }^{63}$ Despite recent reports involving the complement system in the pathogenesis of $\mathrm{D}+\mathrm{HUS}$, current evidence is not sufficient to support the use of eculizumab for patients with D+HUS. ${ }^{40,42}$

\section{Prognosis and long-term follow-up}

The TMA underlying D+HUS is self-limited; a majority of patients with D+HUS, including children with very severe acute disease courses, experience a full recovery based on clinical and laboratory assessments. ${ }^{16,18}$ Nevertheless, a significant percentage are affected by long-term, mostly renal, sequelae. Unlike mortality rate, risk for long-term renal sequelae has not significantly changed over the years, remaining, on average, around $30 \% .{ }^{18,80}$ Pneumococcal HUS is managed based on similar principles, but tends to be associated with a worse prognosis. ${ }^{2}$ Children with identifiable sequelae such as hypertension, proteinuria, or impaired renal function should be treated accordingly; generally, long-term treatment with an angiotensin-converting enzyme inhibitor is indicated. ${ }^{81,82}$ Ideally, these patients may benefit from ongoing nephrology follow-up. However, children that seem to have made a full recovery may also benefit from long-term monitoring for development of hypertension and proteinuria, as the extent of lost nephrons during the acute phase of the disease may be significant but masked by compensation of remaining nephrons. ${ }^{80}$

aHUS, particularly the familial form, has been reported to be associated with a poor prognosis; without specific treatment, patients experience relapses and ongoing disease activity leading to end-stage kidney failure in most cases. ${ }^{77}$ The disease tends to recur after kidney transplantation, leading to graft loss in a majority of patients. ${ }^{77}$ Nevertheless, recent advances in understanding the pathophysiology of aHUS have opened the way to new treatment protocols using PE and complement inhibitors, which are likely to significantly improve outcomes in these patients. ${ }^{83,84}$

\section{Summary}

HUS is a rare but very serious complication of infections with toxin-producing pathogens or genetic mutations leading to a TMA. The vast majority of cases in childhood, $90 \%$, are caused by EHEC/Shiga toxin-producing E. coli infections. Currently, no specific treatment modalities have been shown to influence outcomes of D+HUS. Comprehensive supportive nutritional and hemodynamic management coupled with peritoneal dialysis or hemodialysis when indicated are associated with best outcomes and minimal mortality. Prevention of EHEC infections continues to be the best and most efficient strategy against D+HUS. In patients suspected of aHUS, PE should be instituted without delay and, once diagnosis is confirmed, treatment with a complement inhibitor should be considered.

\section{Disclosure}

The author reports no conflicts of interest in this work.

\section{References}

1. Siegler RL. The hemolytic uremic syndrome. Pediatr Clin North Am. 1995;42(6):1505-1529.

2. Brandt J, Wong C, Mihm S, et al. Invasive pneumococcal disease and hemolytic uremic syndrome. Pediatrics. 2002;110(2 Pt 1):371-376.

3. Geerdink LM, Westra D, van Wijk JA, et al. Atypical hemolytic uremic syndrome in children: complement mutations and clinical characteristics. Pediatr Nephrol. 2012;27(8):1283-1291.

4. Barbour T, Johnson S, Cohney S, Hughes P. Thrombotic microangiopathy and associated renal disorders. Nephrol Dial Transplant. 2012;27(7): 2673-2685.

5. Bell BP, Goldoft M, Griffin PM, et al. A multistate outbreak of Escherichia coli O157:H7-associated bloody diarrhea and hemolytic uremic syndrome from hamburgers. The Washington experience. JAMA. 1994;272(17):1349-1353.

6. Riley LW, Remis RS, Helgerson SD, et al. Hemorrhagic colitis associated with a rare Escherichia coli serotype. $N$ Engl $J$ Med. 1983;308(12):681-685.

7. Brandt JR, Fouser LS, Watkins SL, et al. Escherichia coli O 157:H7associated hemolytic-uremic syndrome after ingestion of contaminated hamburgers. J Pediatr. 1994;125(4):519-526.

8. MacDonald IA, Gould IM, Curnow J. Epidemiology of infection due to Escherichia coli O157: a 3-year prospective study. Epidemiol Infect. 1996;116(3):279-284.

9. Slutsker L, Ries AA, Greene KD, Wells JG, Hutwagner L, Griffin PM. Escherichia coli O157:H7 diarrhea in the United States: clinical and epidemiologic features. Ann Intern Med. 1997;126(7):505-513.

10. Miceli S, Jure MA, de Saab OA, et al. A clinical and bacteriological study of children suffering from haemolytic uraemic syndrome in Tucuman, Argentina. Jpn J Infect Dis. 1999;52(2):33-37. 
11. Rodrigue DC, Mast EE, Greene KD, et al. A university outbreak of Escherichia coli O157:H7 infections associated with roast beef and an unusually benign clinical course. J Infect Dis. 1995;172(4): $1122-1125$.

12. Carter AO, Borczyk AA, Carlson JA, et al. A severe outbreak of Escherichia coli O157:H7-associated hemorrhagic colitis in a nursing home. N Engl J Med. 1987;317(24):1496-1500.

13. Ostroff SM, Kobayashi JM, Lewis JH. Infections with Escherichia coli O157:H7 in Washington State. The first year of statewide disease surveillance. JAMA. 1989;262(3):355-359.

14. Pai CH, Ahmed N, Lior H, Johnson WM, Sims HV, Woods DE. Epidemiology of sporadic diarrhea due to verocytotoxin-producing Escherichia coli: a two-year prospective study. J Infect Dis. 1988;157(5): 1054-1057.

15. Rowe PC, Orrbine E, Lior H, et al. Risk of hemolytic uremic syndrome after sporadic Escherichia coli O157:H7 infection: results of a Canadian collaborative study. Investigators of the Canadian Pediatric Kidney Disease Research Center. J Pediatr. 1998;132(5):777-782.

16. Grisaru S, Midgley JP, Hamiwka LA, Wade AW, Samuel SM. Diarrheaassociated hemolytic uremic syndrome in southern Alberta: a long-term single-centre experience. Paediatr Child Health. 2011;16(6): $337-340$.

17. Nathanson S, Kwon T, Elmaleh M, et al. Acute neurological involvement in diarrhea-associated hemolytic uremic syndrome. Clin J Am Soc Nephrol. 2010;5(7):1218-1228.

18. Garg AX, Suri RS, Barrowman N, et al. Long-term renal prognosis of diarrhea-associated hemolytic uremic syndrome: a systematic review, meta-analysis, and meta-regression. JAMA. 2003;290(10): 1360-1370.

19. Noris M, Caprioli J, Bresin E, et al. Relative role of genetic complement abnormalities in sporadic and familial aHUS and their impact on clinical phenotype. Clin J Am Soc Nephrol. 2010;5(10):1844-1859.

20. Salvadori M, Bertoni E. Update on hemolytic uremic syndrome: diagnostic and therapeutic recommendations. World J Nephrol. 2013;2(3):56-76.

21. Ariceta G, Besbas N, Johnson S, et al; European Paediatric Study Group for HUS. Guideline for the investigation and initial therapy of diarrheanegative hemolytic uremic syndrome. Pediatr Nephrol. 2009;24(4): 687-696.

22. Cummings KC, Mohle-Boetani JC, Werner SB, Vugia DJ. Populationbased trends in pediatric hemolytic uremic syndrome in California, 1994-1999: substantial underreporting and public health implications. Am J Epidemiol. 2002;155(10):941-948.

23. Griffin PM, Tauxe RV. The epidemiology of infections caused by Escherichia coli O157:H7, other enterohemorrhagic E. coli, and the associated hemolytic uremic syndrome. Epidemiol Rev. 1991;13:60-98.

24. Tarr PI, Hickman RO. Hemolytic uremic syndrome epidemiology: a population-based study in King County, Washington, 1971 to 1980. Pediatrics. 1987;80(1):41-45.

25. Waters JR, Sharp JC, Dev VJ. Infection caused by Escherichia coli O157:H7 in Alberta, Canada, and in Scotland: a five-year review, 1987-1991. Clin Infect Dis. 1994;19(5):834-843.

26. Verweyen HM, Karch H, Brandis M, Zimmerhackl LB. Enterohemorrhagic Escherichia coli infections: following transmission routes. Pediatr Nephrol. 2000;14(1):73-83.

27. Lopez EL, Diaz M, Grinstein S, et al. Hemolytic uremic syndrome and diarrhea in Argentine children: the role of Shiga-like toxins. $J$ Infect Dis. 1989;160(3):469-475.

28. Bonnet R, Souweine B, Gauthier G, et al. Non-O157:H7 Stx2-producing Escherichia coli strains associated with sporadic cases of hemolyticuremic syndrome in adults. J Clin Microbiol. 1998;36(6):1777-1780.

29. Keene WE, Sazie E, Kok J, et al. An outbreak of Escherichia coli O157:H7 infections traced to jerky made from deer meat. JAMA. 1997;277(15):1229-1231.

30. Tarr PI, Gordon CA, Chandler WL. Shiga-toxin-producing Escherichia coli and haemolytic uraemic syndrome. Lancet. 2005;365(9464): 1073-1086.
31. Belongia EA, Osterholm MT, Soler JT, Ammend DA, Braun JE, MacDonald KL. Transmission of Escherichia coli O157:H7 infection in Minnesota child day-care facilities. JAMA. 1993;269(7):883-888.

32. Butler T. Haemolytic uraemic syndrome during shigellosis. Trans $R$ Soc Trop Med Hyg. 2012;106(7):395-399.

33. Constantinescu AR, Bitzan M, Weiss LS, et al. Non-enteropathic hemolytic uremic syndrome: causes and short-term course. Am J Kidney Dis. 2004;43(6):976-982.

34. Taylor CM, Machin S, Wigmore SJ, Goodship TH; working party from the Renal Association, the British Committee for Standards in Haematology and the British Transplantation Society. Clinical practice guidelines for the management of atypical haemolytic uraemic syndrome in the United Kingdom. Br J Haematol. 2010;148(1):37-47.

35. Gasser C, Gautier E, Steck A, Siebenmann RE, Oechslin R. [Hemolytic-uremic syndrome: bilateral necrosis of the renal cortex in acute acquired hemolytic anemia]. Schweiz Med Wochenschr. 1955;85(38-39):905-909. German.

36. Karmali MA, Petric M, Lim C, Fleming PC, Steele BT. Escherichia coli cytotoxin, haemolytic-uraemic syndrome, and haemorrhagic colitis. Lancet. 1983;2(8362):1299-1300.

37. Karmali MA, Steele BT, Petric M, Lim C. Sporadic cases of haemolytic-uraemic syndrome associated with faecal cytotoxin and cytotoxin-producing Escherichia coli in stools. Lancet. 1983;1(8325): 619-620.

38. Rahaman MM, JamiulAlam AK, Islam MR, Greenough WB 3rd. Shiga bacillus dysentery associated with marked leukocytosis and erythrocyte fragmentation. Johns Hopkins Med J. 1975;136(2):65-70.

39. Karmali MA. Infection by verocytotoxin-producing Escherichia coli. Clin Microbiol Rev. 1989;2(1):15-38

40. Petruzziello-Pellegrini TN, Marsden PA. Shiga toxin-associated hemolytic uremic syndrome: advances in pathogenesis and therapeutics. Curr Opin Nephrol Hypertens. 2012;21(4):433-440.

41. Louise CB, Obrig TG. Shiga toxin-associated hemolytic uremic syndrome: combined cytotoxic effects of shiga toxin and lipopolysaccharide (endotoxin) on human vascular endothelial cells in vitro. Infect Immun. 1992;60(4):1536-1543.

42. Noris M, Mescia F, Remuzzi G. STEC-HUS, atypical HUS and TTP are all diseases of complement activation. Nat Rev Nephrol. 2012;8(11): 622-633.

43. Lemaire M, Frémeaux-Bacchi V, Schaefer F, et al. Recessive mutations in DGKE cause atypical hemolytic-uremic syndrome. Nat Genet. 2013;45(5):531-536.

44. Nelson JM, Griffin PM, Jones TF, Smith KE, Scallan E. Antimicrobial and antimotility agent use in persons with shiga toxin-producing Escherichia coli O157 infection in FoodNet Sites. Clin Infect Dis. 2011;52(9):1130-1132.

45. Ake JA, Jelacic S, Ciol MA, et al. Relative nephroprotection during Escherichia coli O157:H7 infections: association with intravenous volume expansion. Pediatrics. 2005;115(6):e673-e680.

46. Hickey CA, Beattie TJ, Cowieson J, et al. Early volume expansion during diarrhea and relative nephroprotection during subsequent hemolytic uremic syndrome. Arch Pediatr Adolesc Med. 2011;165(10):884-889.

47. King CK, Glass R, Bresee JS, Duggan C; Centers for Disease Control and Prevention. Managing acute gastroenteritis among children: oral rehydration, maintenance, and nutritional therapy. MMWR Recomm Rep. 2003;52(RR-16):1-16.

48. Guarino A, Albano F, Ashkenazi S, et al; European Society for Paediatric Gastroenterology, Hepatology, and Nutrition; European Society for Paediatric Infectious Diseases. European Society for Paediatric Gastroenterology, Hepatology, and Nutrition/European Society for Paediatric Infectious Diseases evidence-based guidelines for the management of acute gastroenteritis in children in Europe. J Pediatr Gastroenterol Nutr. 2008;46 Suppl 2:S81-S122.

49. Dundas S, Todd WT, Neill MA, Tarr PI. Using antibiotics in suspected haemolytic-uraemic syndrome: antibiotics should not be used in Escherichia coli O157:H7 infection. BMJ. 2005;330(7501):1209; author reply 1209. 
50. Ikeda K, Ida O, Kimoto K, Takatorige T, Nakanishi N, Tatara K. Effect of early fosfomycin treatment on prevention of hemolytic uremic syndrome accompanying Escherichia coli O157:H7 infection. Clin Nephrol. 1999;52(6):357-362.

51. Pavia AT, Nichols CR, Green DP, et al. Hemolytic-uremic syndrome during an outbreak of Escherichia coli O157:H7 infections in institutions for mentally retarded persons: clinical and epidemiologic observations. J Pediatr. 1990;116(4):544-551.

52. Proulx F, Turgeon JP, Delage G, Lafleur L, Chicoine L. Randomized, controlled trial of antibiotic therapy for Escherichia coli O157:H7 enteritis. J Pediatr. 1992;121(2):299-303.

53. Smith KE, Wilker PR, Reiter PL, Hedican EB, Bender JB, Hedberg CW. Antibiotic treatment of Escherichia coli O157 infection and the risk of hemolytic uremic syndrome, Minnesota. Pediatr Infect Dis J 2012;31(1):37-41.

54. Wong CS, Jelacic S, Habeeb RL, Watkins SL, Tarr PI. The risk of the hemolytic-uremic syndrome after antibiotic treatment of Escherichia coli O157:H7 infections. N Engl J Med. 2000;342(26):1930-1936.

55. Panos GZ, Betsi GI, Falagas ME. Systematic review: are antibiotics detrimental or beneficial for the treatment of patients with Escherichia coli O157:H7 infection? Aliment Pharmacol Ther. 2006;24(5):731-742.

56. Safdar N, Said A, Gangnon RE, Maki DG. Risk of hemolytic uremic syndrome after antibiotic treatment of Escherichia coli O157:H7 enteritis: a meta-analysis. JAMA. 2002;288(8):996-1001.

57. Thomas DE, Elliott EJ. Interventions for preventing diarrhea-associated hemolytic uremic syndrome: systematic review. BMC Public Health. 2013;13:799

58. Ikeda K, Ida O, Kimoto K et al. Predictors for the development of haemolytic uraemic syndrome with Escherichia coli O157:H7 infections with focus on the day of illness. Epidemiol Infect 2000;124:343-349.

59. TrachtmanH,CnaanA, ChristenE, etal; Investigators of theHUS-SYNSORB $\mathrm{Pk}$ Multicenter Clinical Trial. Effect of an oral Shiga toxin-binding agent on diarrhea-associated hemolytic uremic syndrome in children: a randomized controlled trial. JAMA. 2003;290(10):1337-1344.

60. Grif K, Dierich MP, Karch H, Allerberger F. Strain-specific differences in the amount of Shiga toxin released from enterohemorrhagic Escherichia coli $\mathrm{O} 157$ following exposure to subinhibitory concentrations of antimicrobial agents. Eur J Clin Microbiol Infect Dis. 1998;17(11):761-766.

61. Kimmitt PT, Harwood CR, Barer MR. Induction of type 2 Shiga toxin synthesis in Escherichia coli O157 by 4-quinolones. Lancet. 1999;353(9164):1588-1589.

62. Walterspiel JN, Ashkenazi S, Morrow AL, Cleary TG. Effect of subinhibitory concentrations of antibiotics on extracellular Shiga-like toxin I. Infection. 1992;20(1):25-29.

63. Menne J, Nitschke M, Stingele R, et al. Validation of treatment strategies for enterohaemorrhagic Escherichia coli O104:H4 induced haemolytic uraemic syndrome: case-control study. BMJ. 2012;345:e4565.

64. Bitzan M, Poole R, Mehran M, et al. Safety and pharmacokinetics of chimeric anti-Shiga toxin 1 and anti-Shiga toxin 2 monoclonal antibodies in healthy volunteers. Antimicrob Agents Chemother. 2009;53(7):3081-3087.

65. Taylor CM, Bitzan M, Reymond D. Shigatec: a Phase II study assessing monoclonal antibodies against Shiga toxin 1 and 2 in Shiga toxin-producing E.coli-infected children. Pediatr Nephrol. 2011;26(9):1595-1596.

66. Bitzan M. Treatment options for HUS secondary to Escherichia coli O157:H7. Kidney Int Suppl. 2009;(112):S62-S66.
67. MeadPS, Griffin PM. Escherichia coli O157:H7. Lancet. 1998;352(9135) 1207-1212.

68. Goldstein SL, Somers MJ, Baum MA, et al. Pediatric patients with multiorgan dysfunction syndrome receiving continuous renal replacement therapy. Kidney Int. 2005;67(2):653-658.

69. Sutherland SM, Zappitelli M, Alexander SR, et al. Fluid overload and mortality in children receiving continuous renal replacement therapy: the prospective pediatric continuous renal replacement therapy registry. Am J Kidney Dis. 2010;55(2):316-325.

70. Andreoli SP. Acute kidney injury in children. Pediatr Nephrol. 2009;24(2):253-263.

71. Andreoli SP. Management of acute kidney injury in children: a guide for pediatricians. Paediatr Drugs. 2008;10(6):379-390.

72. Bunchman TE. Treatment of acute kidney injury in children: from conservative management to renal replacement therapy. Nat Clin Pract Nephrol. 2008;4(9):510-514.

73. Rousseau E, Blais N, O'Regan S. Decreased necessity for dialysis with loop diuretic therapy in hemolytic uremic syndrome. Clin Nephrol. 1990;34(1):22-25.

74. Grisaru S, Morgunov MA, Samuel SM, et al. Acute renal replacement therapy in children with diarrhea-associated hemolytic uremic syndrome: a single center 16 years of experience. Int J Nephrol. 2011;2011:930539.

75. Tarr PI, Neill MA, Allen J, Siccardi CJ, Watkins SL, Hickman RO. The increasing incidence of the hemolytic-uremic syndrome in King County, Washington: lack of evidence for ascertainment bias. Am J Epidemiol. 1989;129(3):582-586.

76. Pape L, Ahlenstiel T, Kreuzer M, et al. Early erythropoietin reduced the need for red blood cell transfusion in childhood hemolytic uremic syndrome: a randomized prospective pilot trial. Pediatr Nephrol. 2009;24(5):1061-1064.

77. Noris M, Remuzzi G. Atypical hemolytic-uremic syndrome. $N$ Engl J Med. 2009;361(17):1676-1687.

78. Zuber J, Fakhouri F, Roumenina LT, Loirat C, Frémeaux-Bacchi V; French Study Group for aHUS/C3G. Use of eculizumab for atypical haemolytic uraemic syndrome and C3 glomerulopathies. Nat Rev Nephrol. 2012;8(11):643-657.

79. Lapeyraque AL, Malina M, Fremeaux-Bacchi V, et al. Eculizumab in severe Shiga-toxin-associated HUS. N Engl J Med. 2011;364(26): 2561-2563.

80. Rosales A, Hofer J, Zimmerhackl LB, et al. Need for long-term follow-up in enterohemorrhagic Escherichia coli-associated hemolytic uremic syndrome due to late-emerging sequelae. Clin Infect Dis. 2012;54(10):1413-1421.

81. Caletti MG, Balestracci A, Missoni M, Vezzani C. Additive antiproteinuric effect of enalapril and losartan in children with hemolytic uremic syndrome. Pediatr Nephrol. 2013;28(5):745-750.

82. Caletti MG, Missoni M, Vezzani C, et al. Effect of diet, enalapril, or losartan in post-diarrheal hemolytic uremic syndrome nephropathy. Pediatr Nephrol. 2011;26(8):1247-1254.

83. Fakhouri F, Fremeaux-Bacchi V, Loirat C. Atypical hemolytic uremic syndrome: from the rediscovery of complement to targeted therapy. Eur J Intern Med. 2013;24(6):492-495.

84. Noris M, Remuzzi G. Managing and preventing atypical hemolytic uremic syndrome recurrence after kidney transplantation. Curr Opin Nephrol Hypertens. 2013;22(6):704-712.

International Journal of Nephrology and Renovascular Disease

\section{Publish your work in this journal}

The International Journal of Nephrology and Renovascular Disease is an international, peer-reviewed open-access journal focusing on the pathophysiology of the kidney and vascular supply. Epidemiology, screening, diagnosis, and treatment interventions are covered as well as basic science, biochemical and immunological studies. The journal welcomes original research, clinical studies, reviews \& evaluations, expert opinion and commentary, case reports and extended reports. The manuscript management system is completely online and includes a very quick and fair peerreview system, which is all easy to use. Visit http://www.dovepress.com/ testimonials.php to read real quotes from published authors. 